\title{
Comparative study of mtDNA in species of the genus Adalia (Coleoptera: Cocinellidae) and origin of ancient mitochondrial haplotypes in the gene pool of Adalia bipunctata
}

\author{
ILYA ZAKHAROV and ELENA SHAIKEVICH \\ N.I. Vavilov Institute of General Genetics, 3 ul. Gubkina, Moscow 119991, Russia; e-mails: iaz34@mail.ru; \\ elenashaikevich@mail.ru
}

Key words. Coleoptera, Cocinellidae, Adalia bipunctata, COI, ITS2, Rickettsia

\begin{abstract}
Fifteen different mitochondrial haplotypes of the mtDNA gene COI encoding cytochrome C oxidase subunit I were identified in the 127 individuals of Adalia bipunctata studied. Two mitochondrial haplotypes, H9 and H10, differed greatly from the others. The mitochondrial polymorphism in A. bipunctata is ancient, though its age remains to be evaluated. It is shown that mitochondrial haplotypes $\mathrm{H} 9$ and $\mathrm{H} 10$ and others coexisted in the original population of $A$. bipunctata before it spread throughout Eurasia from Western Europe to the Baikal Area, and before the differentiation of the subspecies A. bipunctata fasciatopunctata, which differs from the European form in its elytral pattern. In order to evaluate the possible origin of the ancient mitochondrial haplotypes in the gene pool of $A$. bipunctata sequences of the mtDNA gene $C O I$ and of the rRNA second internal transcribed spacer of the four species of Adalia: A. bipunctata, A. decempunctata, A. frigida and A. tetraspilota, were compared. It is suggested that infection with Rickettsia had an important role in the preservation of the mitochondrial haplotypes $\mathrm{H} 9$ and $\mathrm{H} 10$ during the evolution of Adalia.
\end{abstract}

\section{INTRODUCTION}

The ladybirds of the genus Adalia are a popular object of research in ecological and population genetics. The elytral and pronotum patterns of the species in this genus are very variable. The analyses of the variation in these morphological traits were mainly carried out on species of ladybird belonging to the genus Adalia (Lus, 1928; Majerus, 1994). As shown by genetic studies, the forms of $A$. bipunctata found in nature are not only phenotypically but also genotypically distinct; each colour phenotype corresponds to a particular genotype (Lus, 1928, 1932; Majerus, 1994). The first report of molecular polymorphism in $A$. bipunctata is that of Schulenburg et al. (2002). It is known that at least two species (A. bipunctata and $A$. decempunctata) are infected with symbiotic bacteria (Hurst et al., 1999; Von der Schulenburg et al., 2001). Under the term symbiosis are included any type of persistent biological interaction (ie mutualistic, commensalistic or parasitic). In ladybirds these bacteria kill male progeny. Since these male-killing bacteria are transferred transovarially bacterial infection is correlated with host mitochondrial haplotypes (Schulenburg et al., 2002). Studies of the mitochondrial polymorphism in populations of the two-spot ladybird beetle, A. bipunctata, by Schulenburg et al. (2002) revealed two peculiar mitochondrial haplotypes. These mitochondrial haplotypes, H9 and H10, were considerably different from the other. An attempt to evaluate the time of divergence of the mitochondrial haplotype H10 by Jiggins \& Tinsley (2005) gave an age of 2-2.5 million years. Consequently, this mitochondrial polymorphism is referred to as ancient.
Which taxon of the genus Adalia was the source of the mitochondrial haplotypes $\mathrm{H} 9$ and $\mathrm{H} 10$ ? There are three species that are quite similar to $A$. bipunctata L.: $A$. decempunctata L., A. tetraspilota Hope and A. frigida Schneid. (Lusis, 1973). A. decempunctata occurs throughout the temperate zones in Europe and coexists there with $A$. bipunctata. These species can mate, but the eggs do not develop (Lusis, 1973). A. tetraspilota is an Indian species, which is found in the southern part of the former Soviet Union republics in Middle Asia. For example, in Tashkent (Uzbekistan) Lusis reports that these two species coexist, which we can confirm based on our observations. Lusis states that these two species are reproductively isolated (Lusis, 1973). Finally, A. frigida inhabits the northern part of Eurasia, from Scandinavia to Yakutia. Based on our observations, A. bipunctata and A. frigida coexist in Arkhangelsk. A. frigida occurring in North America (Wingo, 1952; Smith, 1953) and Russia (Lusis, 1973) has been studied. It is not clear to what extent these species are reproductively isolated.

In this work we compared the DNA sequences of the mtDNA gene COI and the rRNA second internal transcribed spacer (ITS2) of individuals of $A$. bipunctata with mitochondrial haplotypes $\mathrm{H} 9$ and $\mathrm{H} 10$ and also sequences common in this species with homologous DNA sequences from other species of the genus Adalia. We aimed to evaluate the possible origin of these ancient mitochondrial haplotypes in the gene pool of Adalia bipunctata and to analyze the role of male-killing bacteria in their spread. 
TABLE 1. Estimates of the average evolutionary divergence recorded between sequence pairs in different species of Adalia.

\begin{tabular}{|c|c|c|c|c|c|c|}
\hline & A. bipunctata* & A. frigida & A. tetraspilota & A. decempunctata & $\mathrm{H} 9 * *$ & $\mathrm{H} 10^{* * *}$ \\
\hline \multicolumn{7}{|l|}{ A. bipunctata* } \\
\hline A. frigida & 0.043 & & & & & \\
\hline A. tetraspilota & 0.062 & 0.066 & & & & \\
\hline A. decempunctata & 0.120 & 0.138 & 0.129 & & & \\
\hline $\mathrm{H} 9 * *$ & 0.043 & 0.023 & 0.067 & 0.136 & & \\
\hline $\mathrm{H} 10 * * *$ & 0.067 & 0.070 & 0.069 & 0.135 & 0.067 & \\
\hline
\end{tabular}

* A. bipunctata (includes all mitochondrial haplotypes except H9, H10); ** A. bipunctata mitochondrial haplotype H9; *** A. bipunctata mitochondrial haplotype H10.

\section{MATERIAL AND METHODS}

The DNA was isolated from adult individuals of the following species of Adalia: A. bipunctata (collected in Russia: in St. Petersburg, June 2009; Arkhangelsk, August 2010; Kem, August, 2010; in the eastern part of Russia in Ulan-Ude, Baikal Area, September 2010 and also in Uzbekistan, Tashkent, June 2011); A. decempunctata (collected in Sweden, Stockholm, Kungens Kurva area, 2001); A. frigida (collected in Arkhangelsk, August 2005); A. tetraspilota (collected in Uzbekistan, Tashkent, June 2011).

DNA was isolated from the ladybirds using the DIAtom ${ }^{\mathrm{TM}}$ DNA Prep Kit (Isogen, Moscow, Russia). Polymerase chain reaction (PCR) was run in thermocyclers GeneAmp ${ }^{\mathrm{R}}$ PCR System 2700 (Applied Biosystems, Foster City, CA, USA) with amplification kits GenePak ${ }^{\mathrm{TM}}$ PCR Core (Isogene, Moscow, Russia), $1 \mathrm{mkg}$ of extracted DNA and 5 pmol of each primer.

The mtDNA gene $C O I$ was amplified using primers $\mathrm{LCO}$ and HCO (Folmer et al., 1994). PCR conditions were: step $1,94^{\circ}, 1$ min; step 2 with 5 cycles $\left(94^{\circ} \mathrm{C}, 1 \mathrm{~min}, 45^{\circ} \mathrm{C}, 1.5 \mathrm{~min}, 72^{\circ} \mathrm{C}, 1.5\right.$ min); step 3 with 35 cycles $\left(94^{\circ} \mathrm{C}, 1 \mathrm{~min}, 50^{\circ} \mathrm{C}, 1.5 \mathrm{~min}, 72^{\circ} \mathrm{C}\right.$, $1 \mathrm{~min}$ ); final synthesis at $72^{\circ} \mathrm{C}, 5 \mathrm{~min}$.

The primers $\mathrm{C} 1-\mathrm{j}-1951$ and $\mathrm{C} 1-\mathrm{N}-2618$ (Schulenburg et al., 2002) were used to amplify the most variable region in the middle part of the gene COI. The ITS2 region was amplified using the primers complementary to the $5,8 \mathrm{~S}$ and $28 \mathrm{~S}$ rRNA (Porter \& Collins, 1991). PCR conditions for these two primers sets were: heating for $5 \mathrm{~min}$ at $94^{\circ} \mathrm{C}$; then 35 cycles: denaturing at $94^{\circ} \mathrm{C}, 30 \mathrm{~s}$, annealing at $55^{\circ} \mathrm{C}, 40 \mathrm{~s}$, synthesis at $72^{\circ} \mathrm{C}, 40 \mathrm{~s}$; final synthesis at $72^{\circ} \mathrm{C}, 10 \mathrm{~min}$.

After electrophoresis on a $1 \%$ agarose gel (Sigma, St. Louis, $\mathrm{MO}$, USA), the amplified DNA fragments were isolated from the gel using the JetQuiCk Gel Extraction Spin Kit (Genomed, Löhne, Germany) and then sequenced using both primers on an ABI 310 automated sequencer using the ABI PRISM BigDye Terminator Cycle Sequencing kit (Applied Biosystems, Foster City, CA, USA). The newly identified sequences were submitted to GenBank, accession numbers of the gene COI JQ757048-JQ757053 and of the ITS2 JX459794-JX459830.

The sequences obtained were analyzed using software Chromas (http://www.technelysium.com.au) and the phylogenetic analysis in MEGA4 (Tamura et al., 2007). The evolutionary distances for $\mathrm{COI}$ were computed using five methods: (1) the p-distance method; (2) the Jukes-Cantor method commonly used to evaluate evolution of protein molecules; (3) the Tamura-Nei method commonly used to estimate the number of nucleotide substitutions in the control region of mitochondrial DNA; (4) the Kimura 2-parameter method, which is a simple way of estimating the evolutionary rate of base substitutions by comparing nucleotide sequences; and (5) the Tajima-Nei method in MEGA4 developed for estimating the evolutionary distance between nucleotide sequences (Tamura et al., 2007).
The values of divergence for the sequences of the COI gene obtained using all the above methods were practically identical (not shown). Table 1 presents the data obtained using the p-distance method. This method corresponds to the method used to evaluate the criteria for intra- and inter-species sequence divergence of mitochondrial genes in animals (Kartavtsev, 2011). The number of base differences per site averaged over all COI sequence pairs between groups is shown in Table 1. All results are based on the pairwise analysis of 20 sequences of $C O I$. Among them 15 different mitochondrial haplotypes of $A$. bipunctata were studied. Mitochondrial haplotypes of A. decempunctata and $A$. tetraspilota were identified using two individuals of each species. Since we had the progeny of one individual of $A$. frigida the mtDNA of only one individual of this species (mother) was studied. Analyses were conducted in MEGA4 using the Maximum Composite Likelihood model. Codon positions included were $1 \mathrm{st}+2 \mathrm{nd}+3 \mathrm{rd}$. All positions containing gaps and missing data were eliminated from the dataset (Complete deletion option). There were a total of 970 positions of the COI gene in the final dataset. The analysis of nucleotide polymorphism from aligned DNA sequences of both COI and ITS2 data was done using the DNA Sequence Polymorphism (DnaSP) software (Librado \& Rozas, 2009).

Phylogenetic analyses were conducted in MEGA4 (Tamura et al., 2007). The bootstrap consensus trees inferred using the Neighbour-Joining method was taken to represent the evolutionary history of Adalia based on COI and ITS2. The percentage of replicate trees in which the associated taxa clustered together in the bootstrap test (1000 replicates) is shown next to the branches. The trees are drawn to scale, with branch lengths in the same units as those of the evolutionary distances used to infer the phylogenetic tree. The evolutionary distances were computed using the Maximum Composite Likelihood method and are expressed in terms of the number of base substitutions per site. Codon positions included were $1 \mathrm{st}+2 \mathrm{nd}+3 \mathrm{rd}$. All positions containing gaps and missing data were eliminated from the dataset (Complete deletion option).

\section{RESULTS}

\section{Mitochondrial DNA}

We compared the sequences of the mtDNA gene $C O I$ of four species of Adalia: A. bipunctata, A. decempunctata, A. frigida and A. tetraspilota. Two COI gene fragments were analyzed: the 5'-terminal Barcode fragment, traditionally used in comparative analysis of species and the middle fragment, which is considered to be the most variable (Schulenburg et al., 2002). The size of the PCR product was about $700 \mathrm{bp}$ in both cases. The amplified fragments were sequenced. The primers were selected to produce overlapping amplified sequences, thus allowing 
[

\#A.bipunctata $\mathrm{H} 1$ \#A.bipunctata H2 \#A.bipunctata H3 \#A.bipunctata $\mathrm{H} 4$ \#A.bipunctata $\mathrm{H} 7$ \#A.bipunctata H11 \#A.bipunctata $\mathrm{H} 12$ \#A.bipunctata H13 \#A.bipunctata H1 \#A.bipunctata H15 \#A.bipunctata H16 \#A.bipunctata $\mathrm{H} 17$ \#A.bipunctata H18 \#A.bipunctata H1O \#A.bipunctata H9 \#A. frigida 1

\#A.tetraspilota 1 \#A. tetraspilota 2 \#A. decempunctata
\#A. decempunctata

\section{[}

\#A.bipunctata $\mathrm{H} 1$ \#A.bipunctata H2 \#A.bipunctata H3 \#A.bipunctata $\mathrm{H} 4$ \#A.bipunctata $\mathrm{H} 7$ \#A.bipunctata H11 \#A.bipunctata H12 \#A.bipunctata H13 \#A.bipunctata H14 \#A.bipunctata H15 \#A.bipunctata H16 \#A.bipunctata H17 \#A.bipunctata H18 \#A.bipunctata H10 \#A.bipunctata H9 \#A.frigida 1

\#A.tetraspilota 1 \#A.tetraspilota $\# A$. decempunctata 1
$\# A$. decempunctata 2 $\begin{array}{lllllllll}11111 & 1111111111 & 1222222222 & 2222222333 & 3333333333 & 3333333444 & 4444444444 & 4445555555]\end{array}$ $\begin{array}{lllllllllll}12333455 & 5666022445 & 5566678889 & 9023344456 & 6677889000 & 0111233335 & 5667789011 & 2334455578 & 9990011122]\end{array}$ $\begin{array}{llllllllllllllll}3907349812 & 7036209140 & 3725670395 & 8181836752 & 4536284036 & 9289403691 & 7162879814 & 9584556976 & 2581703625]\end{array}$

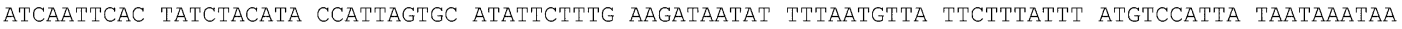

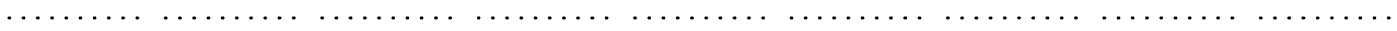

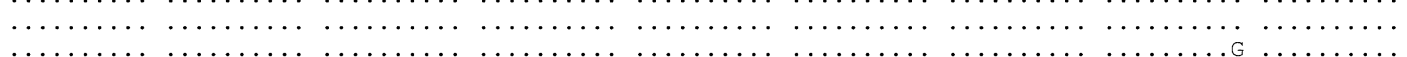

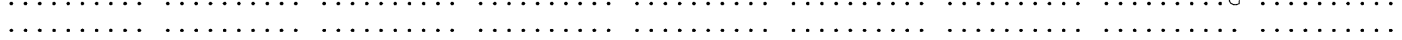

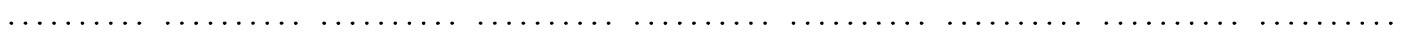

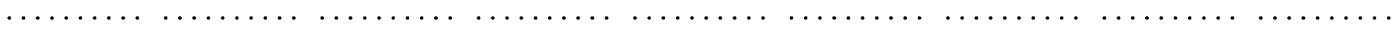

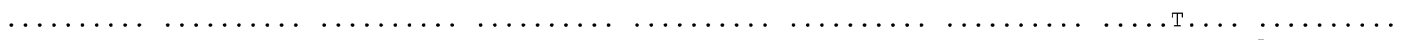

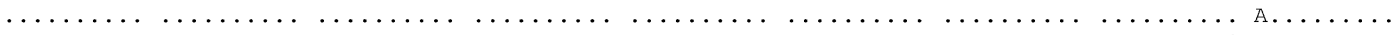

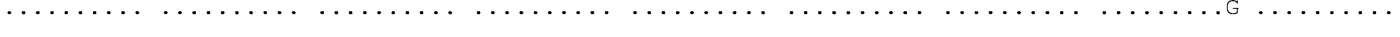

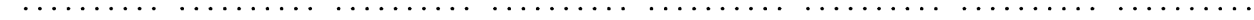
.

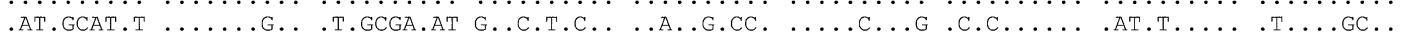

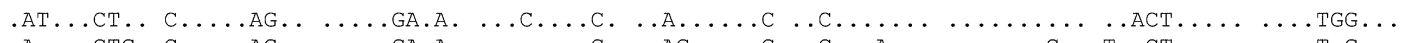

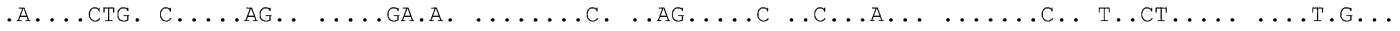

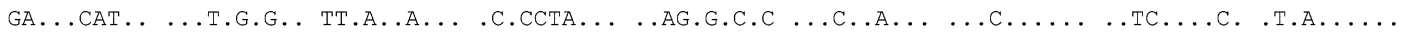

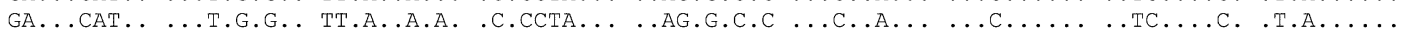
TC.G..AT.T .TC.C...AT TTT...TA.T ........ TGAGATTCC. CA.TC.AAGT CCTACCT.CA . .T.T.CAA. .TT.T...GG TC.G..AT.T .TC.C...AT TTT...TA.T ........ TGAGATTC. CA.TC.AAGT CCTACCT.CA .T.T.CAA. .TT.T...GG

$\begin{array}{llllllllllllllll}5555555555 & 5555666666 & 6666667777 & 7777777777 & 7777788888 & 8888888888 & 8889999999 & 9999999999 & \text { ] }\end{array}$ $\begin{array}{lllllllllllll}3334667788 & 8999011233 & 5667790122 & 2234556667 & 7889900112 & 2334555688 & 9990011233 & 4445556667\end{array}$ TATTAACTTA AGTACCTTTA AAATTAGTAC ATTTTTCAAT ATATTACCAT CTGTAAACAA ACTTATTTAC TTATCATGGC VIMNTI

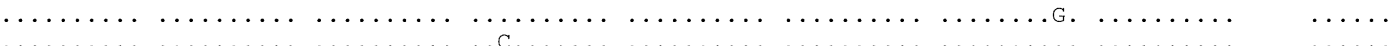
$\cdots \cdots \cdots \cdots \cdots \cdots \cdots$

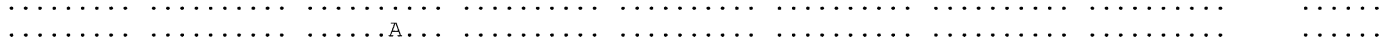

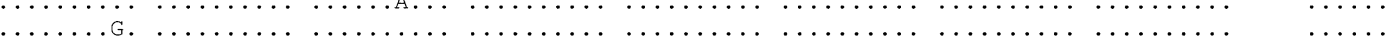

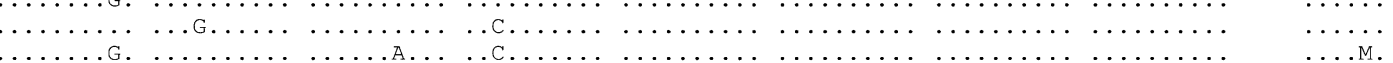

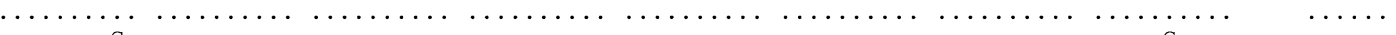

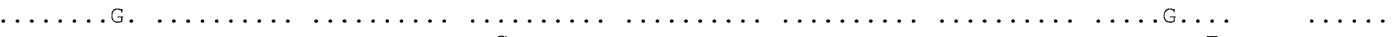

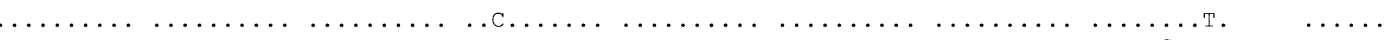

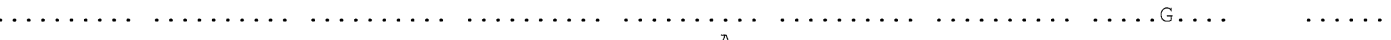

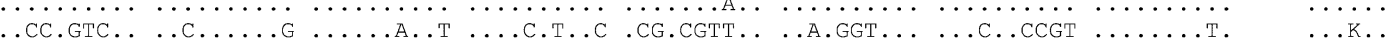

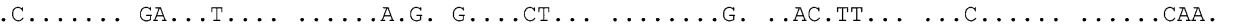

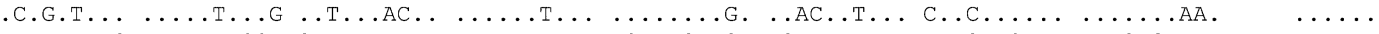

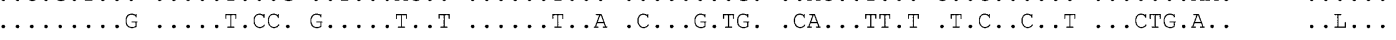

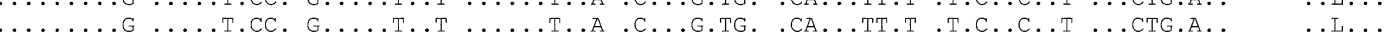
CG.CT .... GA.TTC.A. .GTCCCA.GT .GCCCA.TCA G..AA.TA.C TCA..TT. .TC.GC..T CCC.T.CT IVL... CG.CT.... GA..TTC.A. .GT.CCA.GT .GCCCA.TCA G..AA.TA.C TCA...TT. .TC.GC..T CCC.T.CT IVL...

Fig. 1. Alignment of the different nucleotide and amino acid sites of the gene COI. H1-H18 - mitochondrial haplotypes of $A$. bipunctata.

us to combine the sequences for further analysis. The 970-bp combined fragment was analyzed.

\section{Mitochondrial divergence between species}

Of all the 20 mitochondrial haplotypes recorded in four species, 170 nucleotide sites were variable and 144 of them parsimony-informative. Five nucleotide substitutions, including three at the first nucleotide position, result in an amino acid substitution (Fig. 1). Methionine (M) common to all $A$. bipunctata and $A$. frigida studied is replaced by Leucine (L) in $A$. decempunctata and $A$. tetraspilota. The $A$. decempunctata studied differed from the other species at position 88: Isoleicine (I) is replaced by Valine (V) and $\mathrm{V}$ by $\mathrm{L}$ at position 89 (Fig. 1). The minimum evolutionary divergence (nucleotide variations per site) recorded between $A$. bipunctata and A. frigida was $4.3 \%$. Maximum differences of about $13 \%$ were recorded between $A$. decempunctata and other species (Table 1).

\section{Mitochondrial polymorphism within $A$. bipunctata}

Fifteen different mitochondrial haplotypes were identified in the 127 individuals of $A$. bipunctata studied. The numbering of the mitochondrial haplotypes follows Schulenburg et al. (2002) and continues on with the newly identified (H11-H18) mitochondrial haplotypes. The main part of the sample, 56 (44\%) individuals were of mitochondrial haplotype H1, $31(24.4 \%)$ of H10, 20 $(16 \%)$ of H7, 5 (4\%) of H9, $3(2.4 \%)$ of H3, 2 (1.6\%) of $\mathrm{H} 2,2(1.6 \%)$ of $\mathrm{H} 11$ and one individual $(0.8 \%)$ each of $\mathrm{H} 4, \mathrm{H} 12-\mathrm{H} 18$ Among the sequences of the COI gene from $A$. bipunctata 85 sites were found to be variable with most of the sequences differing in from 1-4 nucleotides. There are 40 variable sites in mitochondrial haplotypes H9 and H10. Most of the nucleotide substitutions are synonymous. $\mathrm{H} 13$ differs from $\mathrm{H} 1$ by four nucleotide substitutions, one of which results in the substitution of the amino-acid Methionine (M) for Threonine (T), H10 differs from $\mathrm{H} 1$ by 60 nucleotide substitutions, resulting in the substitution of Lysine $(\mathrm{K})$ for Asparagine $(\mathrm{N})$. No other nucleotide substitution results in an amino acid substitution (Fig. 1). Most of the nucleotide sequences of the gene $C O I$ of $A$. bipunctata studied varied by less than $0.3 \%$. Exceptions are the DNA sequences of $A$. bipunctata, common for the mitochondrial haplotypes $\mathrm{H} 9$ and H10, which differ from the other A. bipunctata haplotypes by 4.3 and $6.7 \%$, respectively. 


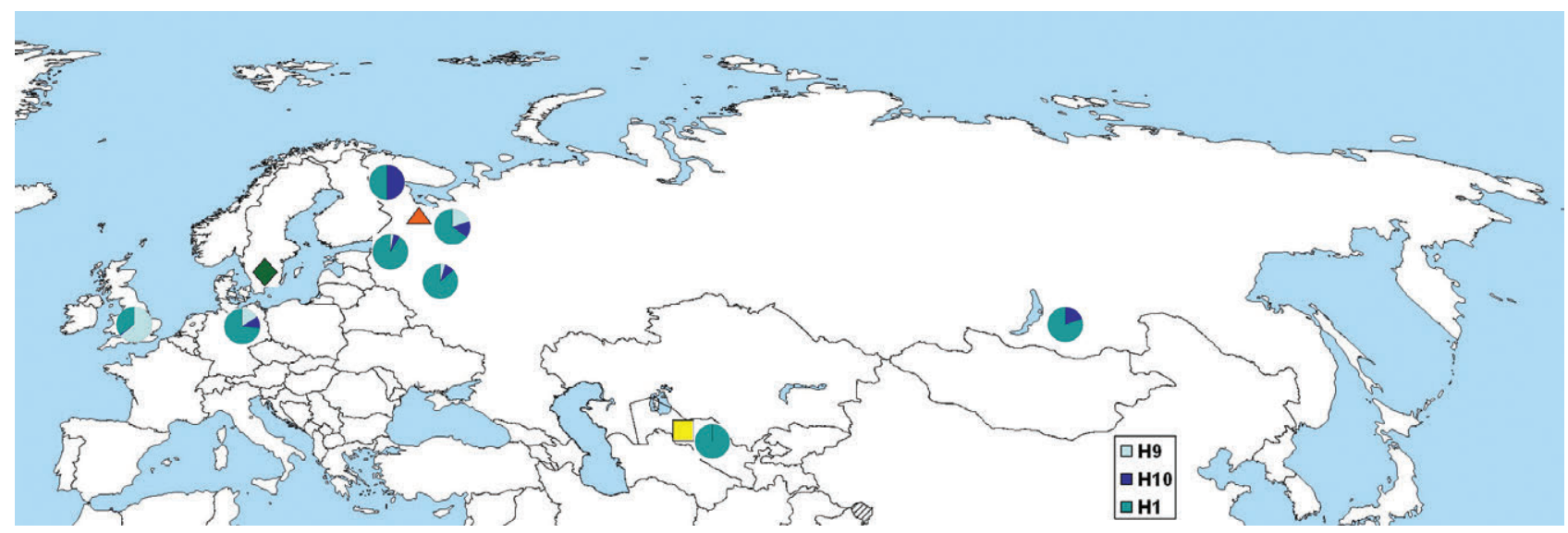

Fig. 2. Map of distribution of the species of Adalia and of known mtDNA haplotypes of A. bipunctata. Circles denote A. bipunctata and the coloured sectors in the pie diagrams correspond to mitochondrial haplotypes H1 (in H1 we include H1 and all other mitochondrial haplotypes, except H9 and H10), H9 and H10. Haplotypes recorded for Moscow (Russia) and Bielefeld (Germany) (Schulenburg et al., 2002) and Cambridge (England) (Schulenburg et al., 2002; Jiggins \& Tinsley, 2005). Triangles mark the sites where $A$. frigida was collected, squares $-A$. tetraspilota, diamonds $-A$. decempunctata.

\section{Mitochondrial haplotype H9}

The mitochondrial haplotype $\mathrm{H} 9$, reported in populations of $A$. bipunctata in the northern part of Europe (Schulenburg et al., 2002; Jiggins \& Tinsley, 2005), was found by us in St. Petersburg and Arkhangelsk (Fig. 2). This mitochondrial haplotype differs from the groups "common" for A. bipunctata (all A. bipunctata studied except those with mytotypes $\mathrm{H} 9$ and $\mathrm{H} 10$ ) by $4.3 \%$; this divergence is due to synonymous sites. $\mathrm{H} 9$ differs from $A$. frigida, A. tetraspilota and A. decempunctata mitochondrial haplotypes by $2.3 \%, 6.7 \%$ and $13.6 \%$, respectively. As shown by DNA sequence polymorphism analysis comparing $\mathrm{H} 9$ and other mitochondrial haplotypes of the gene COI fragment studied, 22, 40-48, 62 and 117 sites differed between $\mathrm{H} 9$ and, respectively, $A$. frigida, $A$. bipunctata, A. tetraspilota and A. decempunctata. Minimum average number of nucleotide differences $(\mathrm{Kt})$ and, consequently, minimum nucleotide diversity (PiT) were recorded between mitochondrial haplotype $\mathrm{H} 9$ and common mitochondrial haplotypes of $A$. bipunctata and between $\mathrm{H} 9$ and $A$. frigida. The differences between $\mathrm{H} 9$ and $A$. tetraspilota are about 4 times greater and $A$. decempunctata about 7 times greater (Table 2).

\section{Mitochondrial haplotype $\mathrm{H10}$}

The mitochondrial haplotype $\mathrm{H} 10$ was present in populations in the European part of Russia, St. Petersburg,
Arkhangelsk and Kem, and also in the eastern part of Russia in Ulan-Ude, Baikal Area (Fig. 2). The DNA sequence polymorphism analysis comparing $\mathrm{H} 10$ and other related sequences of the $C O I$ gene revealed 64 segregating sites for $\mathrm{H} 10$ compared with $A$. frigida, 66-68 with $A$. bipunctata, 64 with $A$. tetraspilota and 116 with $A$. decempunctata. The sequences of the type H10 differ from the group of mitochondrial haplotypes common for A. bipunctata by almost $7 \%$, by the same percentage from A. frigida and $A$. tetraspilota, and by $13.5 \%$ from $A$. decempunctata. Evolutionary divergence between $\mathrm{H} 10$ and $A$. bipunctata is more, than between $A$. bipunctata and $A$. frigida and between $A$. bipunctata and $A$. tetraspilota (Table 1). The Kt and PiT values of the mitochondrial haplotype $\mathrm{H} 10$ and those common to A.bipunctata are two times lower than those of $A$. frigida and $A$. tetraspilota, and more than 3 times lower than those of $A$. decempunctata (Table 2).

The mitochondrial haplotype $\mathrm{H} 10$ is equally genetically distant from A. bipunctata, A. frigida and A. tetraspilota, and more distant from $A$. decempunctata. The mitochondrial haplotype $\mathrm{H} 9$ is genetically close to $A$. frigida and $A$. bipunctata, even closer than $\mathrm{H} 10$ to $A$. bipunctata. Genetic distances for $\mathrm{H} 9$ and either $A$. tetraspilota or $A$. decempunctata are practically the same as for H10 (Table 1, Fig. 3). It should be noted that the differences for $\mathrm{H} 9$ and $\mathrm{H} 10$ were similar for all species with the exception of

TABLE 2. Polymorphism in the sequences of mitochondrial haplotypes $\mathrm{H} 9$ and H10 compared with that in other mitochondrial haplotypes.

\begin{tabular}{|c|c|c|c|c|}
\hline & \multicolumn{2}{|c|}{ mitochondrial haplotype H9 } & \multicolumn{2}{|c|}{ mitochondrial haplotype $\mathrm{H} 10$} \\
\hline & $\mathrm{Kt}$ & Pit & $\mathrm{Kt}$ & Pit \\
\hline A. bipunctata $(-\mathrm{H} 9, \mathrm{H} 10)$ & 11.876 & 0.012 & 19.333 & 0.019 \\
\hline A. frigida & 14.667 & 0.015 & 42.667 & 0.044 \\
\hline A. tetraspilota & 41.167 & 0.042 & 42.500 & 0.044 \\
\hline A. decempunctata & 77.833 & 0.080 & 77.167 & 0.079 \\
\hline
\end{tabular}

$\mathrm{Kt}$ - average number of nucleotide differences, PiT - nucleotide diversity (DnaSP v5. Librado \& Rozas, 2009). 


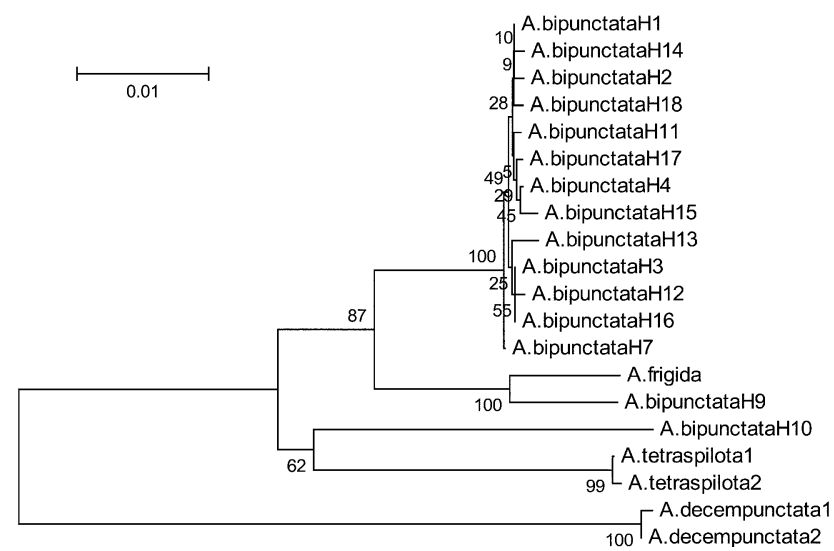

Fig. 3. Phylogeny based on sequences of the COI gene. Evolutionary relationships based on 20 sequences of species of Adalia inferred using the Neighbour-Joining method. H1-H18 different mitochondrial haplotypes of $A$. bipunctata. The optimal tree with the sum of branch lengths $=0.17308113$ is shown (967 positions in the final dataset).

A. frigida, which showed about a 3 times greater similarity with $\mathrm{H} 9$ than $\mathrm{H} 10$.

\section{ITS2 in the ribosomal gene cluster}

As a control, we studied the region of the second transcribed spacer (ITS2) in the ribosomal gene cluster of Adalia. The amplified fragment spanned $900 \mathrm{bp}$. The following individuals were studied: $11 \mathrm{~A}$. bipunctata of mitochondrial haplotype $\mathrm{H} 1,4$ of $\mathrm{H} 9,8$ of $\mathrm{H} 10$ and $3 A$. frigida, $8 \mathrm{~A}$. tetraspilota and $1 \mathrm{~A}$. decempunctata. Unlike mtDNA, the fragment of ITS2 studied was absolutely conserved within a species. The sequences of the ITS2 of all the $A$. bipunctata studied, independent of their mitochondrial haplotypes, were practically identical. The average number of base substitutions per site based on the analysis of $25 \mathrm{~A}$. bipunctata sequences (within species DNA polymorphism) is 0.001 . The ITS2 in other species is also monomorphic (Fig. 4). Divergences recorded between species of Adalia are: $1.8 \%$ between $A$. bipunctata and $A$. frigida, $41.2 \%$ between $A$. bipunctata and $A$. decempunctata, $57.8 \%$ between $A$. bipunctata and $A$. tetraspilota, $41.6 \%$ between $A$. decempunctata and $A$. frigida; A. tetraspilota differs from $A$. frigida and $A$. decempunctata by $58.5 \%$ and $57.7 \%$, respectively. The intergroup genetic diversity, Gst, between the four species of Adalia studied is almost four times lower for mtDNA (Gst: 0.259) than for ITS2 rRNA (Gst: 0.824), but the Haplotype diversity, Hd of mtDNA (Hd 0.988) is higher than that of ITS2 (Hd 0.595).

\section{DISCUSSION}

Earlier (Shaikevich et al., 2012) we studied mitochondrial polymorphism in populations of $A$. bipunctata in relation to their infection with symbiotic bacteria. In this work we compared the variants of $A$. bipunctata mtDNA with that recorded in three closely related species: $A$. decempunctata, A. frigida and A. tetraspilota. All four of the species studied are also characterized by a nuclear

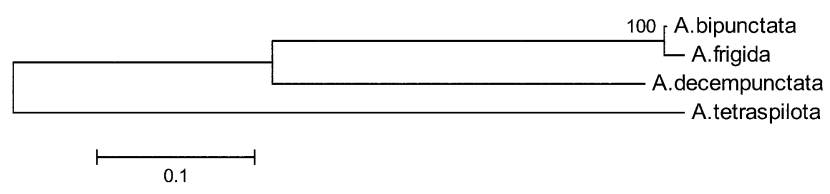

Fig. 4. Evolutionary relationships based on sequences of ITS2. Evolutionary relationships of 4 species of Adalia. The evolutionary history was inferred using the Neighbour-Joining method. The optimal tree with the sum of branch lengths = 1.08817898 is shown (673 positions in the final dataset).

marker, ITS2 rRNA. This is the first molecular genetics study of $A$. frigida and A. tetraspilota.

Among the four species of Adalia studied the most closely related are $A$. bipunctata and $A$. frigida. The phylogenetic relationships of these species have not been previously studied. Our study has revealed a $4.3 \%$ divergence in $C O I$ and $1.8 \%$ in ITS2 between $A$. bipunctata and $A$. frigida. These differences are greater than the values of evolutionary divergence common for subspecies. Independent of the mitochondrial haplotype the ITS2 rRNA sequence of $A$. bipunctata is not polymorphic. ITS2 sequences of $A$. frigida are different from those of $A$. bipunctata and each are monomorphic. Variations in mtDNA, rRNA and the data in the literature on $A$. frigida (Lusis, 1976) allow us to suggest that $A$. frigida is a separate species. However, this species needs further evaluation, and the individuals from geographically remote habitats should be studied.

Based on the gene COI mtDNA, A. decempunctata is the most distant species, whereas based on nucleotide composition of ITS2 A. tetraspilota is evolutionarily most distant from the other species studied. Mutation rate is higher in the rRNA spacer, but the absence of recombination results in a better preservation of rare mutations in the mitochondrial genome; consequently, there is greater diversity of mtDNA haplotypes in species of Adalia and in the related intergroup genetic diversity in rRNA.

Schulenburg et al. (2002) report 10 variable mitochondrial haplotypes in $A$. bipunctata. We found 8 more new mitochondrial haplotypes based on the polymorphism recorded in mtDNA of individuals of $A$. bipunctata from various populations. The most frequent mitochondrial haplotype of the gene $C O I$ in $A$. bipunctata was named H1. Fifteen other mitochondrial haplotypes differed from H1 by $1-4$ substitutions in the most variable 532-bp fragment from the middle part of the gene. Two more mitochondrial haplotypes are also notably different from these 16: $\mathrm{H} 9$ and H10. These mitochondrial haplotypes were recorded in populations of $A$. bipunctata from practically throughout the whole area of the distribution of this species (Fig. 2).

Jiggins \& Tinsley (2005) estimated the divergence time of the mitochondrial haplotype $\mathrm{H} 10$ and other mitochondrial haplotypes as between 2.1-2.5 million years ago. If we assume that the frequency of mutation in the mtDNA of Adalia is equal to that of Drosophila, $6.2 \times 10^{-8}$ (HaagLiautard et al., 2008), then assuming one generation per year the divergence time is 1.13 million years. For an 
average of 1.5 generations per year the divergence time is 750 thousand years.

We attempted to estimate the divergence between the mitochondrial haplotypes $\mathrm{H} 1, \mathrm{H} 9$, and $\mathrm{H} 10$ by comparing 571-bp sequences of the 5' part of the COI gene. These sequences are considered standard and are widely used for genome barcoding. The difference between mitochondrial haplotypes $\mathrm{H} 1$ and $\mathrm{H} 10$ was $7.00 \%$, and between $\mathrm{H} 1$ and $\mathrm{H} 9$ 4.55\%. As shown by Kartavtsev (2011), based on a meta-analysis of the barcoding of thousands of species of animal, insects included, mean intra-populational variation in p-distances (\%) is 0.89 , mean variation between subspecies and twin species is 3.78 and between morphologically distinct species of one genus is 11.06. Therefore, the difference between the mitochondrial haplotypes $\mathrm{H} 1$ and $\mathrm{H} 10$ are close to the level of variation for "distinct" species. Comparison of longer, $970 \mathrm{bp}$, sequences of the COI gene resulted in an evolutionary divergence of $4.3 \%$ between the $\mathrm{H} 9$ and the other mitochondrial haplotypes, and $6.7 \%$ between $\mathrm{H} 10$ and other mitochondrial haplotypes of $A$. bipunctata. This confirms the above conclusions.

It is important to show that the individuals with mitochondrial haplotypes $\mathrm{H} 9$ and $\mathrm{H} 10$ and other mitochondrial haplotypes occur in the same population. Jiggins \& Tinsley (2005) compared samples of individuals carrying mitochondrial haplotypes $\mathrm{H} 10$ and $\mathrm{H} 7$ for the alleles of the nuclear gene g6pd. In this work we compared the sequences of the second internal transcribed spacer of the ribosomal locus from samples of individuals with mitochondrial haplotypes $\mathrm{H} 9, \mathrm{H} 10$ and $\mathrm{H} 1$. Among A. bipunctata, independent of the mitochondrial haplotype, no polymorphism was found in the ITS2 rRNA sequence. Both studies revealed no difference between individuals with different mitochondrial haplotypes.

The oldest age for coexistence of mitochondrial haplotypes $\mathrm{H} 1$ and $\mathrm{H} 10$ in the A. bipunctata gene pool is confirmed by the similarity in the mtDNA polymorphism recorded in European populations and in those from Ulan-Ude, Baikal Area (Fig. 2). However, the population in the Baikal area belongs to a separate subspecies described by Lusis as A. bipunctata fasciatopunctata Fald. (Lusis, 1973). Consequently, mitochondrial haplotypes $\mathrm{H} 10$ and other mitochondrial haplotypes must have coexisted in the original population of $A$. bipunctata before it spread through Eurasia, from western Europe to the Baikal Area and the differentiation of the subspecies A. bipunctata fasciatopunctata, which differs from the European form in its elytral pattern. Therefore, the mitochondrial polymorphism in $A$. bipunctata is in fact ancient, though its precise age remains to be evaluated.

The similarity between the sequence of mitochondrial haplotype $\mathrm{H} 9$ and the respective DNA sequence of $A$. frigida is notable (Fig. 3). Probably, mitochondrial haplotype $\mathrm{H} 9$ originated from an ancestral species of $A$. frigida. It is known that $A$. frigida inhabits a vast area extending from Scandinavia to Yakutia. We had only one female (and her progeny) of this species from Arkhangelsk. Probably, a mitochondrial haplotype close to $\mathrm{H} 9$ is still present in the $A$. frigida gene pool. Thus, it appears promising to study the mtDNA of individuals of $A$. frigida collected from various geographical locations. The mitochondrial haplotype $\mathrm{H} 10$ is very distinct from the common haplotypes of $A$. bipunctata and the sequences of other species (Fig. 3). That it is considerably different from the other haplotypes indicates that this haplotype was incorporated into the A. bipunctata gene pool as a result of interspecies hybridization. Studies of the extant species of the genus Adalia failed to find the ancestral species for the H10 mitotype. Probably, the species from which A. bipunctata got mitochondrial haplotype H10 is now extinct.

In order to understand the factors determining the preservation of the mitochondrial haplotypes H9 and H10 in the $A$. bipunctata gene pool, it is important to take into consideration that only individuals carrying mitochondrial haplotypes $\mathrm{H} 9$ and $\mathrm{H} 10$ are mostly infected with the cytoplasmic symbiotic bacterium Rickettsia $A B$ (Schulenburg et al., 2002; Jiggins \& Tinsley, 2005; Shaikevich et al., 2012), which kills ladybird males at an early stage in their embryonic development. We found no individuals of $A$. bipunctata carrying the other mitochondrial haplotypes infected with Rickettsia, however other studies report cases of infection of individuals with the mitochondrial haplotype H7 (Schulenburg et al., 2002; Jiggins \& Tinsley, 2005). Infected females produce all-female progeny, however, as pointed out long ago by Lus (1947) they have an advantage over non-infected females: the emerging larvae consume non-developing eggs with male embryos and thus obtain sufficient food to complete their initial stages of development. Cytoplasmic bacteria, like mitochondria, are transferred to the progeny transovarially, i.e. through the female line, demonstrating a peculiar effect of linkage disequilibrium with mtDNA. Therefore, the females that produce non-male progeny have a biological advantage, which might account for the continued survival of infected lines and maintenance of the mitochondrial haplotypes "linked" with the infection in the population.

The following scenario may be suggested for the origin of the modern $A$. bipunctata gene pool. Some time ago three similar species coexisted: A. bipunctata, Adalia $Y$ and Adalia $Z$, the two latter carrying mtDNA of type H9 and $\mathrm{H} 10$, respectively. The individuals of Adalia $Y$ and Adalia $Z$ were infected with Rickettsia, which resulted in a sharp decrease in the number of males in these species. The lack of males favoured those Adalia $Y$ and Adalia $Z$ females that mated with males of $A$. bipunctata. The hybrid females were again inseminated by males of $A$. bipunctata. Then the Adalia $Y$ and Adalia $Z$ species became extinct and their mtDNA was incorporated into the gene pool of $A$. bipunctata. In the extension of the range of $A$. bipunctata in Eurasia and its differentiation into subspecies, the mitochondrial haplotypes H9 and H10, linked with Rickettsia, were preserved in most populations of $A$. bipunctata.

A situation similar to what we describe here for Adalia is recorded for Drosophila. In populations of D. quinaria 
there is a peculiar mtDNA variant that differs from the standard at the species-level. Comparison of this mtDNA variant with the mtDNA of known related Drosophila species failed to find the donor species for this haplotype. The flies carrying the peculiar haplotype are infected with the symbiotic bacterium Wolbachia. The authors (Dyer et al., 2011) suggest that the mitochondrial haplotype was introduced into the gene pool by interspecies hybridization with a now extinct species and preserved in the gene pool of $D$. quinaria together with symbiotic bacteria. Wide occurrence of symbiotic bacterial infection in insects suggests that other similar cases will be reported.

Two mitochondrial haplotypes identified earlier in a geographically isolated population of Coccinella septempunctata in Japan, show a $4 \%$ difference from the common haplotypes (Marin et al., 2010). Symbiotic bacteria have not been found in European populations of $C$. septempunctata (M.E.N. Majerus, pers. commun.). However, it would be interesting to know if this is the case in Japan.

ACKNOWLEDGEMENTS. This work was supported by the Program of the RAS Presidium "Life Nature: Present state and problems of development" (Sub-Program. "Dynamics and conservation of Gene Pools"). We thank E. Gupalo for her helpful assistance and comments during the preparation of the manuscript.

\section{REFERENCES}

Dyer K.A., Burke C. \& JAENIKE J. 2011: Wolbachia-mediated persistence of mtDNA from a potentially extinct species. Mol. Ecol. 20: 2805-2817.

Folmer O., Black M., Hoeh W., Lutz R. \& Vrijenhoek R. 1994: DNA primers for amplification of mitochondrial cytochrome c oxidase subunit I from diverse metazoan invertebrates. - Mol. Mar. Biol. Biotechnol. 3: 294-299.

Haag-Liautard C., Crown N., Houle D., Lynch M., Charlesworth B. \& KeIGHTLEy P.D. 2008: Direct estimation of the mitochondrial DNA mutation rate in D. melanogaster. PLoS Biol. 6: 1706-1714.

Hurst G.D.D., Jiggins F.M., Schulenberg J.H.G., Bertrand D., West S.A., Goriacheva I.I., Zakharov I.A., Werren J.H., Stouthamer R. \& Majerus M.E.N. 1999: Male-killing Wolbachia in two species of insect. - Proc. R. Soc. Lond. (B) 266: $735-740$.

JigGINS F.M. \& TINSLEY M.C. 2005: An ancient mitochondrial polymorphism in Adalia bipunctata linked to a sex-ratiodistorting bacterium. - Genetics 171: 1115-1124.

KARTAVTSEV YU.P. 2011: Sequence divergence at mitochondrial genes in animals: applicability of DNA data in genetics of speciation and molecular phylogenetics. - Mar. Genom. 4: 71-81.
Librado P. \& Rozas J. 2009: DnaSP v5: A software for comprehensive analysis of DNA polymorphism data. - Bioinformatics 25: 1451-1452.

LuS YA.YA. 1928: On the inheritance of color and pattern in lady beetles Adalia bipunctata L. and Adalia decempunctata L. - Izv. Byuro Genet. (Leningrad) 6: 89-163 [in Russian, English abstr.].

LuS YA.YA. 1932: An analysis of the dominance phenomenon in the inheritance of the elytra and pronotum colour in Adalia bipunctata. - Trudy Lab. Genet. (Leningrad) 9: 135-162.

LuS YAYA. 1947: Some trends in reproduction of populations of Adalia bipunctata L. maleless lines in populations. - Reports USSR Acad. Sci. 57: 951-954 [in Russian, English abstr.].

LuSIS (LuS) YA.YA. 1973: Taxonomic relations and geographic distribution of ladybirds of the genus Adalia Mulsant. Proc. Latvian State Univ. 184: 5-128 [in Russian, English abstr.].

Lusis (Lus) YA.YA. 1976: [On taxonomy of Adalia frigida Schneider (Coleoptera, Coccinellidae)]. - Genetic and Selectional Studies in Lat. SSR. - Proc. of the Conf. Riga, Zinatne. pp. 3-6 [in Russian].

Majerus M.E.N. 1994: Ladybirds. Harper Collins, London, 366 pp.

Marin J., Crouau-Roy B., Hemptinne J.-L., Lecompte E. \& Magro A. 2010: Coccinella septempunctata (Coleoptera, Coccinellidae): a species complex? - Zool. Scr. 35: 591-602.

Porter C.H. \& Collins F.H. 1991: Species-diagnostic differences in a ribosomal DNA internal transcribed spacer from the sibling species Anopheles freeborni and Anopheles hermsi (Diptera: Culicidae). - Am. J. Trop. Med. Hyg. 45: 271-279.

Shaikevich E.V., Ivshina E.V. \& ZaKharov I.A. 2012: Polymorphism of mtDNA and distribution of cytoplasmic symbionts in populations of the two-spot ladybird beetle Adalia bipunctata. - Russ. J. Genet. 48: 566-570.

SмIтH O.J. 1953: Species, distribution, and host records of the braconid genera Microctonus and Perilitus (Hymenoptera: Braconidae). - Ohio J. Sci. 53: 173-178.

Schulenburg J.H. von der, Habig M., Sloggett J.J., Webberley K.M., Bertrand D., Hurst G.D. \& Majerus M.E.N. 2001: Incidence of male-killing Rickettsia spp. (a-Proteobacteria) in the ten-spot ladybird beetle Adalia decempunctata L. (Coleoptera: Coccinellidae). - Appl. Environ. Microbiol. 67: 270-277.

Schulenburg J.H., Hurst G.D., Tetzlaff D., Booth G.E., ZAKHAROV I.A. \& MAJERUS M.E.N. 2002: History of infection with different male-killing bacteria in the two-spot ladybird beetle Adalia bipunctata revealed through mitochondrial DNA sequence analysis. - Genetics 160: 1075-1086.

Tamura K., Dudley J., Nei M. \& Kumar S. 2007: MEGA4: Molecular Evolutionary Genetics Analysis (MEGA) software version 4.0. - Mol. Biol. Evol. 24: 1596-1599.

WINGo C.W. 1952: The Coccinellidae (Coleoptera) of the upper Mississippi basin. - Iowa State J. Sci. 27: 15-53.

Received April 3, 2012; revised and accepted November 15, 2012 